\title{
EFEITO DO ETHEPHON E DA FRIGOCONSERVAÇÃO NA MATURAÇÃO DE PÊRAS CV. PACKHAM'S TRIUMPH ${ }^{1}$
}

\author{
EDUARDO SEIBERT ${ }^{2}$, CARLOS IGUASSÚ NOGUEIRA BARRADAS ${ }^{3}$, \\ PAULO JUNQUEIRA DE ARAÚJO ${ }^{4}$ e RENAR JOÃO BENDER ${ }^{5}$
}

\begin{abstract}
RESUMO - Este trabalho, realizado em 1996 na Estação Experimental Agronômica da Universidade Federal do Rio Grande do Sul, em Eldorado do Sul, RS, e na Embrapa-Centro de Pesquisa Agropecuária de Clima Temperado (CPACT), em Pelotas, RS, objetivou avaliar o efeito do ethephon aplicado em précolheita e da frigoconservação na maturação da pêra (Pyrus communis L.) cv. Packham's Triumph. O ethephon foi pulverizado nas concentrações de $0,12,5,25,50$ e $100 \mathrm{ppm}$, e as pêras frigorificadas a $-1,0^{\circ} \mathrm{C}$ e $92-96 \%$ de umidade relativa por $0,10,20,40$ e 80 dias. Após os períodos de armazenamento refrigerado, os frutos foram conservados em temperatura ambiente por dois ou oito dias. A firmeza da polpa apresentou uma tendência de diminuição com o aumento das concentrações de ethephon, do período de frigorificação e dos dias à temperatura ambiente. O comportamento da relação sólidos solúveis totais (SST)/acidez titulável (AT) variou mais em função da AT do que dos valores de SST. A relação SST/AT aumentou desde a aplicação dos tratamentos até a colheita. A produção de etileno aumentou com o aumento do período de frigorificação e do número de dias em temperatura ambiente; mas não foi influenciada pela concentração de ethephon.
\end{abstract}

Termos para indexação: Pyrus communis, etileno, armazenagem refrigerada.

\section{EFFECTS OF ETHEPHON AND COLD STORAGE ON RIPENING OF 'PACKHAM'S TRIUMPH' PEARS}

\begin{abstract}
This work was carried out in 1996 at the Estação Experimental Agronômica of the Universidade Federal do Rio Grande do Sul, located in Eldorado do Sul county, RS, and at the EmbrapaCentro de Pesquisa Agropecuária de Clima Temperado (CPACT), located in Pelotas county, RS, Brazil. The objective was to evaluate the effects of ethephon sprays and cold storage on ripening of 'Packham's Triumph' pears. Pear trees were sprayed with ethephon concentrations of $0,12.5,25,50$ on $100 \mathrm{ppm}$ 26 days before harvest. After harvest, the pears were stored at $-1,0^{\circ} \mathrm{C}$ and $92-96 \%$ R.H. for $0,10,20$, 40 or 80 days. After cold storage the pears were kept at room temperature for two or eight days to evaluate shelf life. Fruit firmness decreased with increasing storage periods and days at room temperature. Total soluble solids (TSS)/titratable acidity (TA) ratios increased over time, and were the result mainly of increasing contents of TSS than of the reduction of TA. Ethylene production was not significantly influenced by any concentration of ethephon sprays, though, production rates were higher the longer the cold storage period as well as days at room temperature.
\end{abstract}

Index terms: Pyrus communis, ethylene, cold storage.

\footnotetext{
${ }^{1}$ Aceito para publicação em 5 de março de 1999.

${ }^{2}$ Eng. Agrôn., M.Sc., Faculdade de Agronomia, Universidade Federal do Rio Grande do Sul (UFRGS), Av. Bento Gonçalves, 7717, CEP 91540-000, Porto Alegre, RS

${ }^{3}$ Eng. Agrôn., Ph.D., Prof., Dep. Horticultura e Silvicultura, Faculdade de Agronomia, UFRGS

${ }^{4}$ Eng. Agrôn., Ph.D., Embrapa-Centro de Pesquisa Agropecuária de Clima Temperado (CPACT), Caixa Postal 403, CEP 96001-970 Pelotas, RS.

${ }^{5}$ Eng. Agrôn., Ph.D., Prof. adjunto, Dep. de Horticultura e Silvicultura, UFRGS. E-mail: rjbe@ vortex.ufrgs.br
}

\section{INTRODUÇ̃̃O}

O uso de reguladores de crescimento pode auxiliar no sucesso das culturas, em várias etapas do cultivo. Entre os vários produtos, o ethephon (ácido 2-cloroetil fosfônico), produto comercial Ethrel, é um regulador de crescimento e estimulante, pertencente ao grupo químico do ácido fosfônico (Andrei, 1990). $\mathrm{O}$ ethephon tem sido utilizado para melhorar a coloração dos frutos e antecipar a colheita, com efeitos benéficos sobre atributos de qualidade dos frutos, 
como acidez, teor de sólidos solúveis totais e firmeza da polpa. Em pêras, Edgerton \& Blanpied (1968) demonstraram que o uso de ethephon aplicado em précolheita, acelera o processo de maturação da fruta, principalmente por afetar a firmeza da polpa. Os autores observaram que frutos da cv. Clapp Favorite que receberam tratamento com ethephon, duas semanas antes da data normal de colheita, estavam maduros 10 dias após a aplicação, ao passo que os frutos que não receberam tratamento permaneceram verdes.

A Packham's Triumph é uma das cultivares com maior potencial de produção nas condições climáticas do Rio Grande do Sul e Santa Catarina. O cultivo da pereira está se expandindo principalmente na região dos campos de cima da serra do Estado do Rio Grande do Sul, com a formação de pomares empresariais primordialmente de pereiras européias (Pyrus communis), entre as quais 'Packham's Triumph', 'Williams' ('Bartlett') e 'Red Bartlett'. A aplicação de ethephon, na cultivar em estudo, aliada a diferentes períodos de armazenamento refrigerado, pode contribuir para maturação mais uniforme das pêras. A aplicação em pré-colheita deverá permitir a avaliação do efeito desse regulador de crescimento sobre alguns parâmetros de maturação de pêras (Edgerton \& Blanpied, 1968).

Este trabalho objetivou avaliar o efeito de diferentes concentrações de ethephon em conjunto com diferentes tempos de armazenamento refrigerado e de vida de prateleira, na aceleração da maturação de pêras da cultivar Packham's Triumph.

\section{MATERIAL E MÉTODOS}

As pêras 'Packham's Triumph', usadas neste estudo, foram colhidas em um pomar com 14 anos de idade, enxertadas sobre a cv. Le Conte (Pyrus pyrifolia), localizado no setor de Horticultura e Silvicultura da Estação Experimental Agronômica da Universidade Federal do Rio Grande do Sul (EEA-UFRGS), localizada no município de Eldorado do Sul, RS. O estudo de armazenamento das pêras foi realizado em câmaras frigoríficas existentes na EmbrapaCentro de Pesquisa Agropecuária de Clima Temperado (CPACT), Pelotas, RS.

Foi feita apenas uma aplicação de ethephon, no dia 31 de janeiro de 1996, aproximadamente quatro semanas an- tes da data de colheita, utilizando o produto comercial Ethrel, que contém $240 \mathrm{~g} \mathrm{~L}^{-1}$ de ácido 2-cloroetil fosfônico.

Foram aplicados os seguintes tratamentos: a) testemunha, apenas aplicação de água; b) ethephon 12,5 ppm; c) ethephon $25 \mathrm{ppm}$; d) ethephon $50 \mathrm{ppm}$; e) ethephon $100 \mathrm{ppm}$.

As soluções foram preparadas logo antes de sua aplicação, num volume de 10 litros de solução de cada vez. Os tratamentos foram aplicados com pulverizador costal motorizado, molhando-se bem os frutos até o ponto de escorrimento. As plantas vizinhas às plantas tratadas foram protegidas com uma lona de plástico, para evitar que fossem atingidas pela deriva. Cada tratamento foi aplicado em quatro plantas, previamente selecionadas quanto à sanidade, número de frutos e porte.

No dia da aplicação dos tratamentos foi retirada uma amostra de frutos, para determinar o estádio de maturação. Os frutos apresentavam firmeza da polpa de 72,0 Newtons, teor de sólidos solúveis totais (SST) de $11,5^{\circ} \mathrm{Brix}$, acidez titulável (AT) de 4,1 meq/100 mL e relação SST/AT de 2,80 .

As pêras foram colhidas no dia 26 de fevereiro de 1996 , isto é, 26 dias após a aplicação dos tratamentos com ethephon. A colheita foi feita no período da manhã, sendo os frutos colocados em caixas de plástico de colheita, e transportados até o galpão, onde foram selecionados, por tamanho, ausência de lesões e sintomas de moléstias.

Os frutos selecionados receberam um tratamento de imersão por três minutos em solução fungicida, contendo Benomyl, $60 \mathrm{~g}$ de produto comercial, mais Captan, $240 \mathrm{~g}$ de produto comercial, em 100 litros de água.

Após o tratamento, os frutos foram postos a secar à sombra e no dia seguinte transportados em caixas de plástico de colheita da EEA-UFRGS até a Embrapa-CPACT, onde foi instalado o experimento com armazenamento refrigerado.

$\mathrm{Na}$ Embrapa-CPACT, os frutos foram armazenados em embalagens de madeira do tipo pêssego serrano-madeira. Em cada caixa foram acondicionados cinco frutos, correspondentes a uma repetição, e cada tratamento teve três repetições.

Os frutos foram armazenados em câmara frigorífica por 10, 20, 40 e 80 dias. Ao final de cada período de armazenamento refrigerado, as pêras foram mantidas em temperatura ambiente por dois e oito dias. Os tratamentos sem armazenamento refrigerado (testemunha) foram mantidos em temperatura ambiente, também por dois ou oito dias, logo após a instalação do experimento.

As pêras foram armazenadas em uma câmara frigorífica, com volume de $25 \mathrm{~m}^{3}$, dotada de sistema de refrigeração por ar forçado. A temperatura no interior da câmara 
frigorífica foi mantida a $-1,0^{\circ} \mathrm{C}$ e a umidade relativa entre $92 \%$ e $96 \%$. Um termohigrógrafo foi utilizado para registrar as oscilações de temperatura e umidade no interior da câmara frigorífica.

A determinação da produção de etileno das pêras foi realizada por cromatografia gasosa. Cinco frutos de cada um dos tratamentos foram pesados e colocados em recipientes de vidro, com volume de três litros, e bem fechados, para evitar trocas de oxigênio e gás carbônico com o meio externo. Após uma hora, foram retiradas, com seringas hipodérmicas para insulina, quatro amostras de $1,0 \mathrm{~cm}^{3} \mathrm{de}$ ar do interior de cada recipiente de vidro e injetadas em um cromatógrafo a gás, modelo Varian 3300, equipado com um detector de ionização de chama e coluna do tipo Porapak N. A produção de etileno, expressa em $\mu \mathrm{L} \mathrm{C}_{2} \mathrm{H}_{4} \mathrm{~kg}^{-1} \mathrm{~h}^{-1}$, foi calculada por integração de altura de pico. A temperatura do injetor foi de $80^{\circ} \mathrm{C}$, a da coluna de $90^{\circ} \mathrm{C}$ e do detector de $200^{\circ} \mathrm{C}$.

A firmeza da polpa foi determinada com o uso de um penetrômetro manual Effegi, com ponta de 7,9 mm, sendo a leitura realizada na zona equatorial dos frutos, em dois lados opostos, após retirada a epiderme. A leitura da firmeza obtida em libras pol$^{-2}$ foi, posteriormente, convertida para Newtons $(\mathrm{N})$

Após a determinação do etileno e da firmeza, os frutos foram descascados, cortados e mantidos em sacos de plástico a $-18^{\circ} \mathrm{C}$, até o momento das análises para determinação de teores de SST e AT. Antes das análises, as amostras foram descongeladas e trituradas para obtenção do suco.

As pêras foram analisadas quanto à produção de etileno, firmeza de polpa, teores de SST e AT e relação SST/AT.

A relação SST/AT foi obtida a partir da divisão dos valores de SST pelos valores de AT de cada amostra. O teor de SST foi obtido colocando de duas a três gotas de suco em um refratômetro de bancada, modelo 2WAJ. De cada amostra foram realizadas duas leituras, das quais foi feita a média, expressa em graus Brix. A AT foi determinada por titulação com hidróxido de sódio $0,1 \mathrm{~N}$ de uma amostra de $10 \mathrm{~mL}$ de suco diluída em $90 \mathrm{~mL}$ de água destilada, em agitação constante, até atingir $\mathrm{pH} 8,1$, lido no medidor e analisador de $\mathrm{pH}$ (Centro de Investigación Tecnologica de Frutas y Hortalizas, 1987). O cálculo do teor de acidez foi feito de acordo com a fórmula:

$A=(0,0067 \times V) \times 100 / G$,

onde: $\mathrm{A}=$ acidez total em gramas \% de ácido málico; $0,0067=$ fator de miliequivalentes para expressar a acidez em ácido málico; $\mathrm{V}=$ volume de hidróxido de sódio $0,1 \mathrm{~N}$ utilizado, em $\mathrm{mL} ; \mathrm{G}=$ quantidade da amostra em $\mathrm{mL}$. $\mathrm{O}$ valor da AT foi expresso em miliequivalentes por 100 gramas de ácido málico.
O delineamento experimental utilizado foi o completamente casualizado, em um esquema fatorial $5 \times 5 \times 2$, correspondente a cinco concentrações de ethephon, cinco períodos de armazenamento refrigerado, e dois períodos em temperatura ambiente, respectivamente. Nos casos em que as diferenças das médias foram significativas pelo teste $\mathrm{F}$, a $5 \%$ de probabilidade, foi aplicado o teste de Tukey para comparação das médias.

\section{RESULTADOS E DISCUSSÃO}

A produção de etileno pelas pêras não foi significativamente influenciada pelas concentrações de ethephon (Fig. 1). Embora não tenha havido diferenças significativas entre o efeito das concentrações aplicadas de ethephon, observa-se uma tendência de aumento na produção de etileno dos frutos do tratamento testemunha até a maior concentração. Em comparação com o tratamento testemunha, o aumento na produção de etileno foi de $22,7,44,0$, 49,6 e 53,3\% para os frutos tratados com $12,5,25,50$ e 100 ppm de ethephon, respectivamente.

As condições climáticas variáveis de ano para ano, aliadas às diferenças de local e entre cultivares

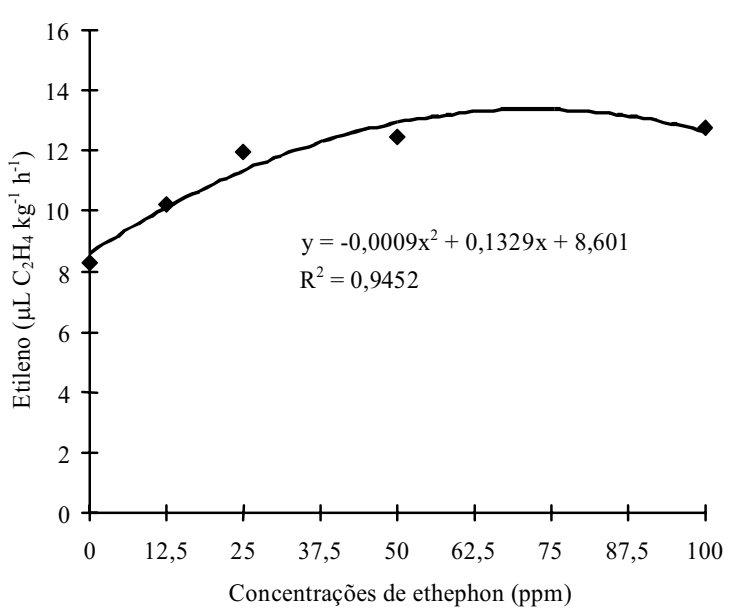

FIG. 1. Evolução da produção de etileno de pêras 'Packham's Triumph' em função de concentrações de ethephon, independentemente de tempos de armazenamento refrigerado a $-1,0^{\circ} \mathrm{C}$ e $92-96 \%$ de U.R. e tempos de vida de prateleira por dois ou oito dias à temperatura ambiente.

Pesq. agropec. bras., Brasília, v.35, n.1, p.55-62, jan. 2000 
podem ter contribuído para esta falta de diferenças estatísticas entre as concentrações de ethephon aplicadas. É possível que também um inverno ameno e uma primavera e verão quentes tenham contribuído para a antecipação em alguns dias na maturação dos frutos. Assim sendo, a colheita realizada 26 dias após a aplicação dos tratamentos, mesmo estando dentro das recomendações de pesquisa, pode ter sido realizada um pouco tarde, estando os frutos em um estádio mais avançado de maturação. Desta forma, houve também aumento na produção de etileno dos frutos-testemunha e dos tratados com apenas 12,5 ppm de ethephon que não diferiram estatisticamente para os tratamentos com 25, 50 e 100 ppm de ethephon. Looney (1971), analisando maçãs 'McIntosh' tratadas com ethephon colhidas em diferentes épocas, observou que a resposta ao ethephon foi menor com o avanço da maturação dos frutos. Segundo o autor, nos frutos mais maduros a habilidade para a produção de etileno endógeno aumentou e a resposta ao ethephon aplicado diminuiu.

A produção de etileno aumentou concomitantemente com o tempo de armazenamento refrigerado (Fig. 2). A produção de etileno após dois dias de prateleira aumentou de $0,32 \mu \mathrm{L} \mathrm{C}_{2} \mathrm{H}_{4}$ nos frutos sem armazenamento para $15,33 \mu \mathrm{L} \mathrm{C}_{2} \mathrm{H}_{4}$ nos frutos com 80 dias de armazenamento. Diferenças estatísticas na produção de etileno ocorreram somente após 80 dias de armazenamento. As cultivares de pêras européias necessitam de um período de frio para que haja significativa produção de etileno e para que inicie a maturação uniforme dos frutos (Mellenthin \& Chen, 1981). Blankenship \& Richardson (1985) observaram que a produção de etileno em pêras 'D'Anjou' aumentou, como resultado do tempo de armazenamento, sendo que a produção de etileno pode ser detectada somente após 40 dias a $-1,0^{\circ} \mathrm{C}$ com 0,52 ppm e atingiu 9,69 ppm de $\mathrm{C}_{2} \mathrm{H}_{4}$ após 78 dias a $-1,0^{\circ} \mathrm{C}$.

Observou-se que com oito dias de prateleira, a produção de etileno foi menor nas amostras de frutos sem armazenamento e com 10 dias de frigoconservação. Nos demais períodos de armazenamento houve aumentos significativos na produção de etileno de acordo com os aumentos de dias em frigorificação até 40 dias. Aos 80 dias a produção estava em níveis semelhantes aos dos 20 dias.
A produção de etileno é estreitamente ligada ao amadurecimento dos frutos (Gussman et al., 1993). O maior aumento na produção de etileno nos frutos armazenados por 20,40 e 80 dias, pode ser resultado do tempo de armazenamento a frio requerido pelas cultivares de pêras européias para iniciar o processo de amadurecimento em associação com os dias à temperatura ambiente necessários para finalizar o amadurecimento. Segundo Blankenship \& Richardson (1985) o pico de produção de etileno para a cv. D'Anjou ocorre entre 43 e 46 dias após o início do armazenamento a $-1,0^{\circ} \mathrm{C}$. Isto pode explicar os valores de etileno obtidos após 20, 40 e 80 dias. As pêras armazenadas por 20 dias talvez tenham sido avaliadas antes da plena produção de etileno, enquanto que os frutos avaliados após 80 dias é possível que já tivessem ultrapassado o ponto de máxima produção de etileno, e que os frutos armazenados por 40 dias, estivessem próximo do pico de produção de etileno, tendo, por isso, apresentado o maior valor.

$\mathrm{O}$ fato de os frutos sem armazenamento e com dez dias de armazenamento apresentarem baixa produção de etileno após oito dias à temperatura ambiente pode ser resultante do pouco ou nenhum tempo de armazenamento a frio que, possivelmente, não foi

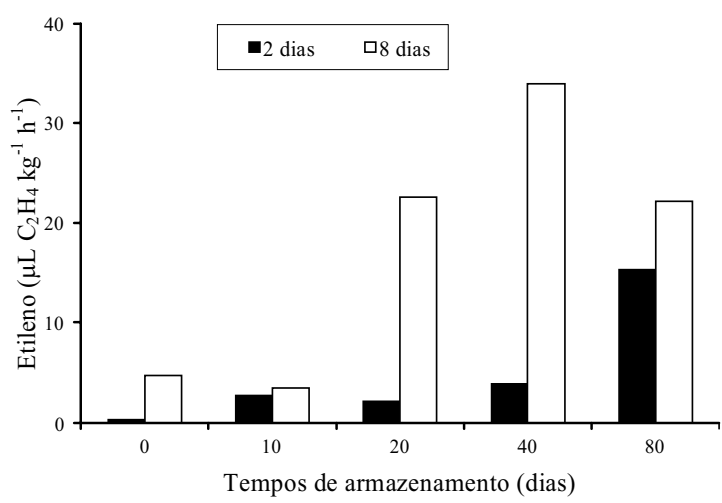

FIG. 2. Evolução da produção de etileno de pêras 'Packham's Triumph' em função de tempos de armazenamento refrigerado a $-1,0^{\circ} \mathrm{C}$ e 92-96\% de U.R. por $0,10,20,40$ ou 80 dias e tempos de vida de prateleira por dois ou oito dias à temperatura ambiente, independentemente de concentrações de ethephon. 
suficiente para satisfazer totalmente a exigência de frio para estimular os processos de maturação.

Com relação ao efeito do tempo de prateleira (Fig. 2), determinou-se que houve um aumento na produção de etileno, de dois para oito dias, em todos os tempos de armazenamento, com diferenças significativas apenas nos frutos armazenados por 20 e 40 dias.

As pêras 'Packham's Triumph' armazenadas por 20 e 40 dias apresentaram aumento nos níveis de etileno de dois para oito dias, provavelmente porque os frutos estavam na fase do climatério. Wang et al. (1985) também observaram um semelhante aumento na produção de etileno, trabalhando com pêras 'Eldorado'. Pêras 'Eldorado' que foram expostas pelo menos por 28 dias a $0^{\circ} \mathrm{C}$ apresentaram o pico de produção de etileno no décimo segundo dia a $20^{\circ} \mathrm{C}$ após armazenamento a frio. Pêras 'Eldorado' armazenadas por 56 dias a $0^{\circ} \mathrm{C}$ apresentaram o pico de produção de etileno no oitavo dia a $20^{\circ} \mathrm{C}$. Wang \& Mellenthin (1972) observaram resultados semelhantes trabalhando com pêras cv. D'Anjou armazenadas por 60 dias $\mathrm{a}-1,1^{\circ} \mathrm{C}$ e transferidas para temperatura ambiente por até oito dias. Nos frutos da cv. Packham's Triumph armazenados por 80 dias, o nível alto de etileno aos dois dias de prateleira pode ter sido resultado do tempo em que os frutos ficaram armazenados $\mathrm{a}-1,0^{\circ} \mathrm{C}$, e a diminuição dos valores de etileno determinada aos oito dias pode ser uma indicação de que os frutos estão em estádio posterior ao climatério. Encurtamento do período para que ocorra o pico de etileno e aumento no pico de etileno a $20^{\circ} \mathrm{C}$ foi observado por Wang et al. (1985) em pêras 'Eldorado' à medida que aumentou o período de armazenamento a $0^{\circ} \mathrm{C}$. A produção de etileno permaneceu baixa e constante após 14 dias a $0^{\circ} \mathrm{C}$ e 15 dias a $20^{\circ} \mathrm{C}$. Nos frutos armazenados por 28 dias a $0^{\circ} \mathrm{C}$ o pico de etileno foi aproximadamente de $12 \mu \mathrm{L}$ após 12 dias a $20^{\circ} \mathrm{C}$, enquanto nos frutos armazenados por 56 dias a $0^{\circ} \mathrm{C}$ foi observada produção de etileno na saída do período de armazenamento, com produção de $7 \mu \mathrm{L} \mathrm{C}_{2} \mathrm{H}_{4}$ atingindo o pico de $29 \mu \mathrm{L}$ após oito dias a $20^{\circ} \mathrm{C}$.

Os tratamentos com ethephon afetaram o comportamento da variável firmeza da polpa (Fig. 3). Os frutos tratados com diferentes concentrações de ethephon apresentaram diferenças significativas de firmeza entre si, dentro de cada tempo de frigoconservação e tempo de prateleira, em apenas três situações. Mesmo havendo poucas diferenças entre as concentrações de ethephon, pode-se dizer que houve a tendência de os frutos tratados com $100 \mathrm{ppm}$ apresentarem aos dois e oito dias de vida de prateleira, e em todos os tempos de frigoconservação, a menor firmeza da polpa. Esta tendência de perda de firmeza com o aumento da concentração tem paralelo, inclusive com outras espécies. Greene et al. (1974) observaram diminuição da firmeza de maçãs 'McIntosh' com o aumento da concentração de ethephon. Os autores observaram que houve diminuição da firmeza do tratamento testemunha para 25 e 75 ppm e destes para o tratamento com 150 ppm de ethephon. Redução na firmeza com o aumento da concentração do ethephon também foi observado por Edgerton \& Blanpied (1968) com pêras 'Clapp Favorite'.

O tempo de permanência dos frutos na câmara teve influência sobre a firmeza da polpa em todos os tratamentos com ethephon em ambos os tempos de prateleira (Fig. 3). A firmeza diminuiu com o aumento da duração do armazenamento. Aos dois dias de prateleira, os frutos de todos os tratamentos com ethephon apresentavam firmeza significativamente menor aos 80 dias de prateleira. Contudo, os frutos tratados com 12,5 e 100 ppm apresentavam já aos 40 dias, firmeza intermediária, enquanto os outros tratamentos foram apresentar diferenças de firmeza somente aos 80 dias.

Avaliando-se os dados de firmeza após oito dias de prateleira, observa-se que os frutos armazenados por 80 dias apresentavam os menores valores de firmeza em todos os tratamentos com ethephon, mas diferenças significativas de firmeza ocorreram já a partir dos 20 dias em todos os tratamentos (Fig. 3).

Ao analisar os resultados dentro do fator tempo de prateleira, observa-se que, de modo geral, a firmeza da polpa dentro de cada concentração de ethephon e tempo de armazenamento foi sempre estatisticamente maior aos dois dias (Fig. 3). Pêras européias, para completar o amadurecimento, necessitam de um período de tempo à temperatura ambiente, sendo que a perda de firmeza dos tecidos acompanha a maturação dos frutos. Segundo Ahmed \& Labavitch (1980), a diminuição da firmeza da polpa é devida, 
basicamente, à dissolução das paredes celulares, com uma grande diminuição no grau de polimerização de ácidos urônicos que geralmente é acompanhado de aumento nos teores de pectinas solúveis.

A relação SST/AT aumentou a partir da aplicação dos tratamentos com ethephon até a colheita (Fig. 4). Isto explica-se pela diminuição nos teores de acidez titulável e também pelo aumento nos teores de SST, ocorrido com o aumento da maturação com o passar do tempo de armazenamento. Unrath (1972) também observou que a diminuição da acidez de maçãs 'Starking' e 'Starkrimson' tratadas com ethephon foi o fator determinante para aumento da relação SST/AT.

A relação SST/AT obtida neste experimento é bastante elevada, em relação aos valores observados em experimentos com outras cv. de pêras e com a cv. Packham's Triumph em particular, e está fora do padrão de qualidade indicado por Fady (1983). O autor cita que para haver qualidade no sabor de pê- ras, a relação SST/AT deve ser inferior a 3,5:1, principalmente para a cv. Passe Crassane. Kappel et al. (1995) também citam, entre as características ideais para pêras, uma relação SST/AT igual a 3,0.

Resultados semelhantes foram obtidos por Francisconi (1992) também com a cv. Packham's Triumph após um mês de armazenamento. Este autor determinou uma variação entre 6,66 a 7,34. É possível que a causa dos altos valores da relação SST/AT observados no presente experimento com pêras 'Packham's Triumph' tratadas com ethephon esteja no fato de os frutos apresentarem acidez muito baixa, visto que os valores de SST estão ao nível dos valores observados em vários trabalhos. Os valores de acidez titulável variaram, após dois dias de prateleira, na faixa entre 1,25 e 2,07 meq/100 mL e, após oito dias de prateleira, entre 1,32 e 2,09 meq/100 mL.

As concentrações de ethephon, aos dois dias de vida de prateleira, apresentaram tendência de dimi-

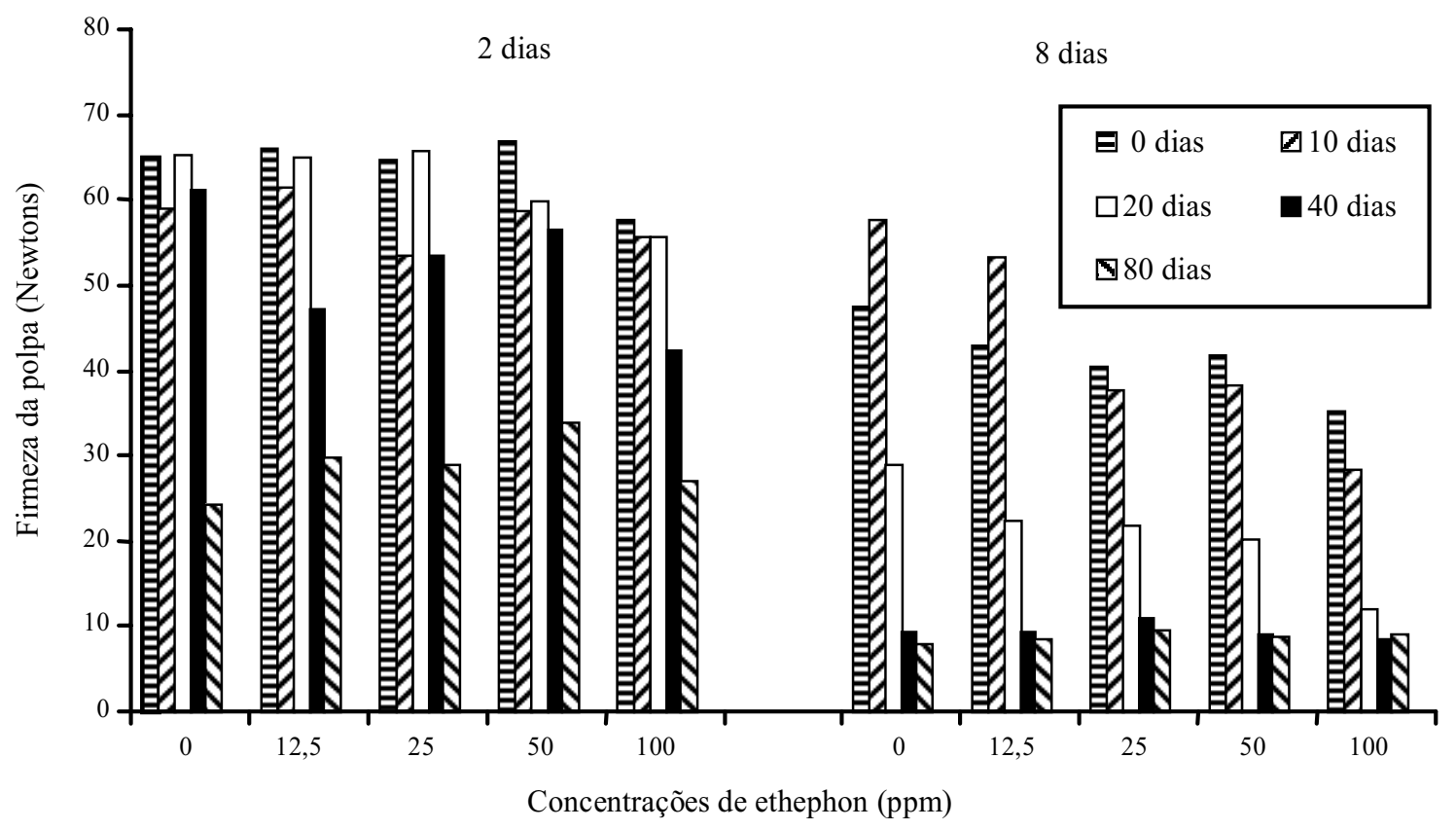

FIG. 3. Evolução da firmeza da polpa de pêras 'Packham's Triumph', após dois ou oito dias de vida de prateleira à temperatura ambiente, quando tratadas 26 dias antes da colheita com $0,12,5,25,50 \mathrm{ou} 100 \mathrm{ppm}$ de ethephon e armazenadas por $0,10,20,40$ ou 80 dias a $-1,0^{\circ} \mathrm{C}$ e $92-96 \%$ de U.R. 
nuição da relação SST/AT dos frutos testemunha até 12,5 ou 25 ppm de ethephon, com aumento após até a concentração de 100 ppm de ethephon (Fig. 4). Esta diminuição, observada até a concentração de 12,5 ou 25 ppm, é, basicamente, atribuída ao aumento dos valores de acidez titulável nestas concentrações. Após oito dias de vida de prateleira, a relação SST/AT apresentou valores que oscilaram com o passar dos dias de armazenamento refrigerado e aos oito dias de vida de prateleira, não foi possível identificar uma tendência de aumento ou diminuição dentro do fator concentrações de ethephon.

Com relação ao efeito provocado pelos dias de armazenamento refrigerado, quando associado a concentrações de ethephon e dias a temperatura ambiente, sobre a relação SST/AT (Fig. 4), observa-se que, de modo geral, após dois dias à temperatura ambiente a relação SST/AT apresentou tendência de diminuição, em todas as concentrações de ethephon, até 20 dias de armazenamento refrigerado. No entan- to, com o aumento de 20 para 80 dias armazenamento refrigerado, houve aumento da relação SST/AT. A maior relação SST/AT observada após 80 dias de armazenamento refrigerado, provavelmente, ocorreu em função do maior tempo em frio que levou a uma mais completa hidrólise de amido, em comparação aos tratamentos com menor tempo de armazenamento refrigerado, aumentando o teor de SST. Além disso, mesmo a baixas temperaturas, há continuidade da respiração que leva a uma diminuição dos ácidos orgânicos e, portanto, da acidez titulável, contribuindo para um aumento da relação SST/AT nestes frutos.

Nos frutos analisados após oito dias de vida de prateleira, a relação SST/AT não apresentou a mesma tendência de crescimento, oscilando com o passar do tempo de armazenamento em frio. Isto é explicado pelo período de tempo prolongado à temperatura ambiente, resultando em um maior consumo de reservas em todos os tratamentos com ethephon.

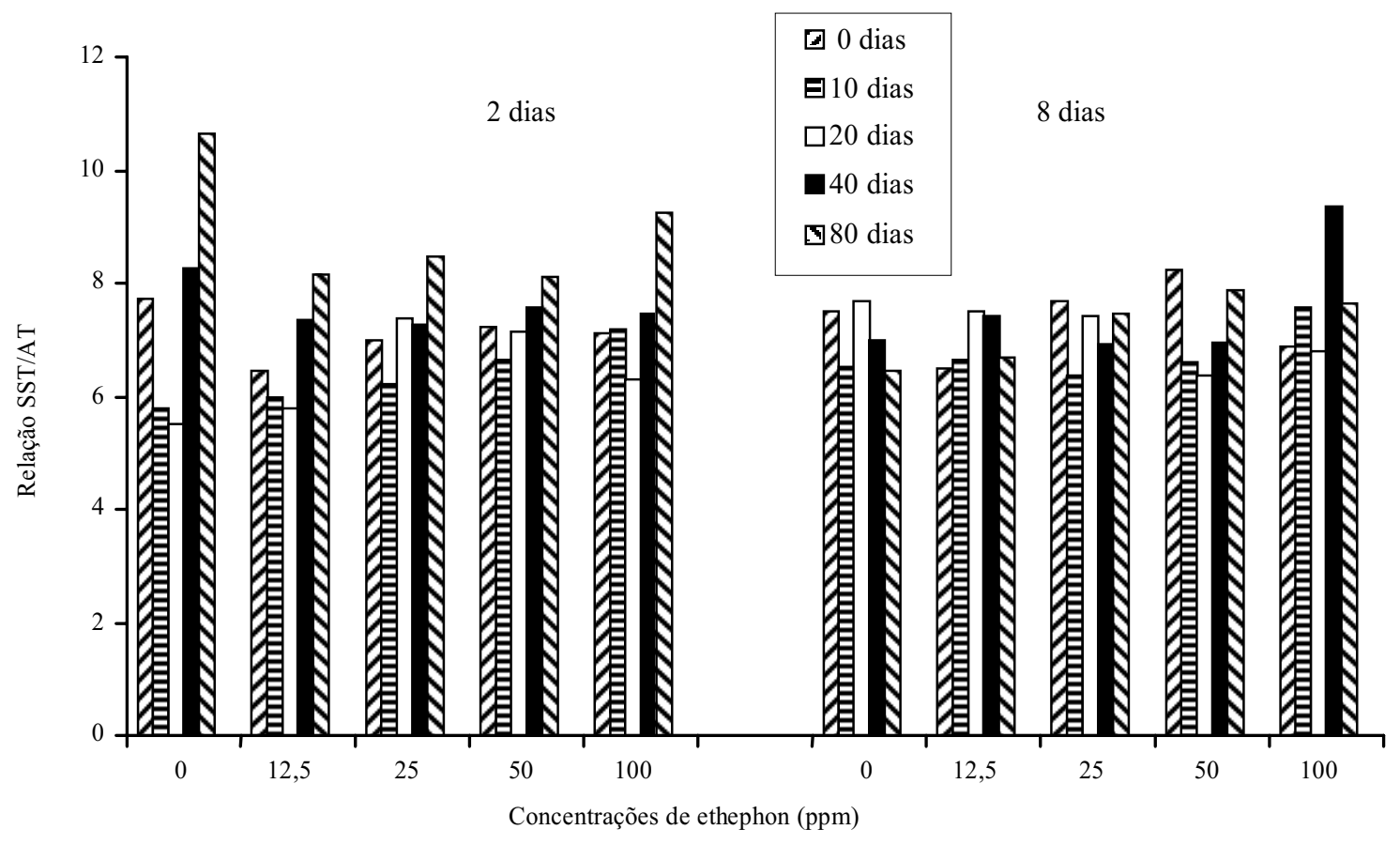

FIG. 4. Evolução da relação SST/AT de pêras 'Packham's Triumph', após dois ou oito dias de vida de prateleira à temperatura ambiente, quando tratadas 26 dias antes da colheita com $0,12,5,25,50 \mathrm{ou} 100 \mathrm{ppm}$ de ethephon e armazenadas por $0,10,20,40$ ou 80 dias a $-1,0^{\circ} \mathrm{C}$ e $92-96 \%$ de U.R. 


\section{CONCLUSÕES}

1. A aplicação de ethephon 26 dias antes da colheita estimula a síntese de etileno de pêras 'Packham's Triumph' ao longo dos períodos de armazenamento refrigerado.

2. A produção de etileno aumenta com o tempo de armazenamento refrigerado e de vida de prateleira, sendo de 20 dias o tempo mínimo em armazenamento refrigerado para estimular a produção de etileno de pêras 'Packham's Triumph'.

3. A firmeza da polpa diminui com o aumento da concentração de ethephon do tempo de armazenamento refrigerado e de vida de prateleira.

\section{REFERÊNCIAS}

AHMED, A.E.; LABAVITCH, J.M. Cell wall metabolism in ripening fruit. I. Cell wall changes in ripening 'Bartlett' pears. Plant Physiology, Rockville, v.65, n.5, p.1009-1013, 1980.

ANDREI, E. (Coord.). Compêndio de defensivos agrícolas. 3.ed. São Paulo : Andrei, 1990. p.204-205.

BLANKENSHIP, S.M.; RICHARDSON, D.G. Development of ethylene biosynthesis and ethyleneinduced ripening in ' $\mathrm{d}$ 'Anjou' pears during the cold requirement for ripening. Journal of the American Society for Horticultural Science, Alexandria, v.110, n.4, p.520-523, 1985.

CENTRO DE INVESTIGACIÓN TECNOLOGICA DE FRUTAS Y HORTALIZAS. Alimentos em general: acidez total. In: TÉCNICAS. [S.l.:s.n.], 1987. c.8, p.3-4.

EDGERTON, L.J.; BLANPIED, G.D. Regulation of growth and fruit maturation with 2-chloroethanephosphonic acid. Nature, Londres, v.219, n.5158, p.1064-1065, 1968.

FADY, C. Critères objectifs de la qualité gustative des fruits: utilisation commerciale de ces critères. Fruits, Paris, v.38, n.7/8, p.547-551, 1983.

FRANCISCONI, A.H.D. Efeito de óleo mineral, cianamida hidrogenada, thidiazuron e nitrato de potássio, na quebra de dormência, produção e qualidade dos frutos de pereira (Pyrus communis L.) cv. Packham's Triumph. Porto Alegre : Universidade Federal do Rio Grande do Sul, 1992. 133p. Dissertação de Mestrado.

GREENE, D.W.; LORD, W.J.; BRAMLAGE, W.J.; SOUTHWICK, F.W. Effects of low ethephon concentrations on quality of 'McIntosh' apples. Journal of the American Society for Horticultural Science, Alexandria, v.99, n.3, p.239242, 1974.

GUSSMAN, C.D.; GOFFREDA, J.C.; GIANFAGNA, T.J. Ethylene production and fruit-softening rates in several apples fruit ripening variants. HortScience, Alexandria, v.28, n.2, p.135-137, 1993.

KAPPEL, F.; FISHER-FLEMING, R.; HOGUE, E.J. Ideal pear sensory attributes and fruit characteristics. HortScience, Alexandria, v.30, n.5, p.988-993, 1995.

LOONEY, N.E. Interaction of ethylene, auxin, and succinic acid-2,2-dimethylhydrazide in apple fruit ripening control. Journal of the American Society for Horticultural Science, Alexandria, v.96, n.3, p.350$353,1971$.

MELLENTHIN, W.M.; CHEN, P.M. Softening and ripening of 'd'Anjou' pears as influenced by simulated transit temperatures. Journal of the American Society for Horticultural Science, Alexandria, v.106, n.1, p.35-38, 1981

UNRATH, C.R. Effects of preharvest applications of ethephon on maturity and quality of several apple cultivars. HortScience, Alexandria, v.7, n.1, p.7779, 1972.

WANG, C.Y.; MELLENTHIN, W.M. Internal ethylene levels during ripening and climateric in Anjou pears. Plant Physiology, Rockville, v.50, n.2, p.311-312, 1972.

WANG, C.Y.; SAMS, C.E.; GROSS, K.C. Ethylene, ACC, soluble polyuronide, and cell wall noncellulosic neutral sugar content in 'Eldorado' pears during cold storage and ripening. Journal of the American Society for Horticultural Science, Alexandria, v.110, n.5, p.687-691, 1985. 